
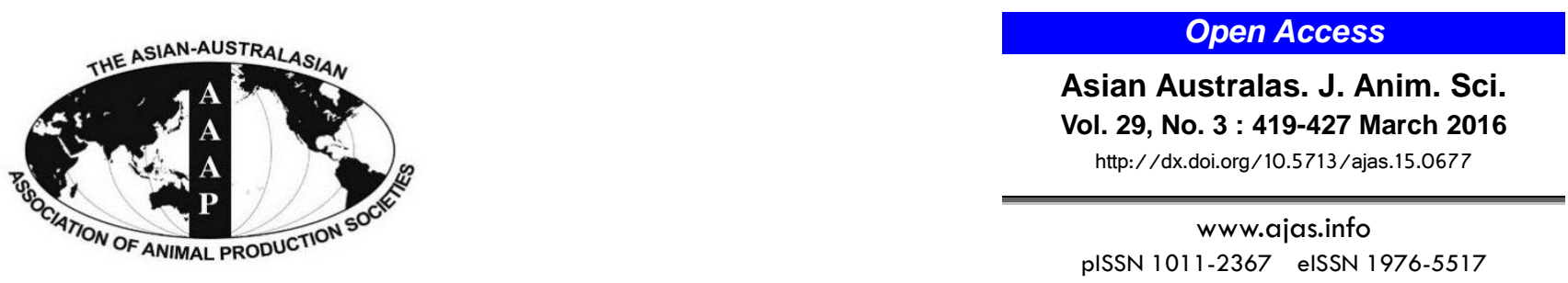

\title{
Heat Shock Protein Augmentation of Angelica gigas Nakai Root Hot Water Extract on Adipogenic Differentiation in Murine 3T3-L1 Preadipocytes
}

\author{
Wenchie Marie L. Lumbera, Joseph dela Cruz ${ }^{1}$, Seung-Hak Yang ${ }^{2}$, and Seong Gu Hwang* \\ Department of Animal Life and Environmental Science, Hankyong National University, Anseong 456-749, Korea
}

\begin{abstract}
There is a high association of heat shock on the alteration of energy and lipid metabolism. The alterations associated with thermal stress are composed of gene expression changes and adaptation through biochemical responses. Previous study showed that Angelica gigas Nakai (AGN) root extract promoted adipogenic differentiation in murine 3T3-L1 preadipocytes under the normal temperature condition. However, its effect in heat shocked 3T3-L1 cells has not been established. In this study, we investigated the effect of AGN root hot water extract in the adipogenic differentiation of murine 3T3-L1 preadipocytes following heat shock and its possible mechanism of action. Thermal stress procedure was executed within the same stage of preadipocyte confluence (G0) through incubation at $42^{\circ} \mathrm{C}$ for one hour and then allowed to recover at normal incubation temperature of $37^{\circ} \mathrm{C}$ for another hour before AGN treatment for both cell viability assay and Oil Red O. Cell viability assay showed that AGN was able to dose dependently (0 to $400 \mu \mathrm{g} / \mathrm{mL})$ increase cell proliferation under normal incubation temperature and also was able to prevent cytotoxicity due to heat shock accompanied by cell proliferation. Confluent preadipocytes were subjected into heat shock procedure, recovery and then AGN treatment prior to stimulation with the differentiation solution. Heat shocked preadipocytes exhibited reduced differentiation as supported by decreased amount of lipid accumulation in Oil Red O staining and triglyceride measurement. However, those heat shocked preadipocytes that then were given AGN extract showed a dose dependent increase in lipid accumulation as shown by both evaluation procedures. In line with these results, real-time polymerase chain reaction (RT-PCR) and Western blot analysis showed that AGN increased adipogenic differentiation by upregulating heat shock protection related genes and proteins together with the adipogenic markers. These findings imply the potential of AGN in heat shock amelioration among 3T3-L1 preadipocytes through heat shock factor and proteins augmentation and enhanced adipogenic marker expression. (Key Words: Angelica gigas Nakai, Heat Shock, Heat Shock Protein, 3T3-L1, Adipogenesis)
\end{abstract}

\section{INTRODUCTION}

Heat stress imperils animal production efficiency through reduction of feed intake and diminishing management, health and reproduction (Collier and Beede, 1985; Collier et al., 2005). Aside from the negative impacts on production parameters, heat load also increases health care cost that can eventually lead to an animal succumbing to severe or chronic thermal stress (Victoria Sanz Fernandez

\footnotetext{
* Corresponding Author: Seong Gu Hwang. Tel: +82-31-670-

5121, E-mail: sghwang@hknu.ac.kr

${ }^{1}$ College of Veterinary Medicine, University of the Philippines Los Banos, 4030, Philippines.

2 National Institute of Animal Science, Rural Development Administration, Wanju 55365, Korea.

Submitted Aug. 14, 2015; Revised Oct. 16, 2015; Accepted Nov. 21, 2015
}

et al., 2015). At the molecular level, thermal stress strongly modifies cell physiology. These modifications are generally composed of changes in the gene expression and biochemical adaptive responses characterized by the impairment of major cellular functions and by an adaptive reprogramming of the cell metabolism (Bensaude et al., 1996). The extent of the alterations depends on the severity of the stress and may lead to cell death (Lacetera et al., 2009).

Biologically, the ability to survive and adapt to thermal stress appears to be a fundamental requirement of cell life, as cell responses are ubiquitous among both eukaryotes and prokaryotes (Lindquist, 1986). Cells from all organisms respond to physiologically relevant variations in temperature by rapidly increasing the expression and synthesis of a selected group of proteins, the heat shock 
proteins (Sonna et al., 2002).

Among cells markedly affected by exposure to thermal stress, adipocytes are of particular interest since they fulfill the dual role of energy storage and thermal insulation (Bernabucci et al., 2009). In a study conducted by Ezure and Amano (2009) about the effects of heat stimulation on adipogenesis, they found out that heat stimulation reduces adipogenesis by decreasing the expression of adipogenesisrelated transcriptional factors.

The use of natural products are widely supported nowadays, Li et al. (2014) presented a study of the potential of grape seed extract to attenuate the responses of jejunum epithelial cells induced by heat stress within a certain range of temperatures in vivo. However, there are no studies describing the use of natural extracts for the amelioration of heat stress with regards to adipogenesis making it an interesting topic to explore and give a deeper consideration.

Angelica gigas Nakai (AGN) is an herbal Korean plant of the Umbelliferae family. Its traditional uses include cognitive and cardiovascular treatment through regularization of blood flow (Park et al., 2012), alleviation of inflammatory disorders (Zhang et al., 2012) as well as gynecological problems and anemia. It is locally known as Dang gui, although specifically 'Korean Dang Gui' (or Cham-dang-gui) (Joo et al., 2010). In a previous study by Dela Cruz et al. (2014) the effects of the root extract of AGN on the differentiation of 3T3-L1 preadipocytes and the possible mechanism of glucose transport were investigated and results suggest that AGN extract may be a potential therapeutic agent for managing type 2 diabetes by promoting the differentiation of adipocytes via the upregulation of peroxisome proliferator-activated receptor gamma (PPAR $\gamma$ ) levels and the activation of the insulin signaling pathway. However, the effect in heat shocked 3T3-L1 cells has not been established. In this study, we investigated the effect of AGN root hot water extract in the adipogenic differentiation of murine 3T3-L1 preadipocytes following heat shock and its possible molecular mechanism of action.

\section{MATERIALS AND METHODS}

\section{Plant material collection, extraction and preparation}

The powdered root of AGN was purchased in a traditional herbal market in South Korea. The hot water extract of AGN was obtained by subjection to the following process. The air dried AGN was freeze dried and pulverized to powder form. An exact amount of 100 grams of the dried AGN powder was soaked into a flask with one liter boiling water $\left(90^{\circ} \mathrm{C}\right)$ for four hours and mixed every 30 minutes. After which, the flask was cooled at room temperature and the suspension was filtered. The filtered aqueous extract was placed in a clean container for freeze drying and stored at $-70^{\circ} \mathrm{C}$. A stock solution was then prepared by dissolving the extract powder in the basal medium and experimental concentrations were diluted. Extracts were sterilized by filtration using $0.22 \mu \mathrm{m}$ pore filter.

\section{Heat shock procedure for preadipocytes}

The heat shock procedure was done on confluent preadipocytes (G0 stage) by incubating the cells in $42^{\circ} \mathrm{C}$ with $95 \%$ humidity and $5 \% \mathrm{CO}_{2}$ for one hour then returning to $37^{\circ} \mathrm{C}$ incubator for recovery of another hour prior to AGN extract treatment for cell viability assay and addition of differentiation solution.

\section{Cell viability analysis}

Different concentrations of AGN root hot water extract was evaluated for its effect on the proliferation of 3T3-L1 preadipocytes incubated under normal $\left(37^{\circ} \mathrm{C}\right)$ and heat stress $\left(42^{\circ} \mathrm{C}\right)$ temperature using Cell counting kit-8 (CCK-8, Dojindo, Tokyo, Japan). The cells seeded in a 96-well plate at a density of $1 \times 10^{4}$ cells/well and were allowed to adhere and settle down at $37^{\circ} \mathrm{C}$. At confluence (G0 stage), the cells were subjected into heat shock procedure (one hour at $42^{\circ} \mathrm{C}$ ) then another hour at $37^{\circ} \mathrm{C}$ as recovery period followed by the addition of increasing concentrations of AGN $(0,50,100,200$, and $400 \mu \mathrm{g} / \mathrm{mL})$ as treatment. After which, they were incubated for both 24 and 48 hours at $37^{\circ} \mathrm{C}$ with $95 \%$ humidity and $5 \% \mathrm{CO}_{2}$. At the end of the treatment period, the media containing AGN was removed and replaced with fresh media containing $10 \mu \mathrm{L} \mathrm{CCK}-8$ solution and incubated at $37^{\circ} \mathrm{C}$ for 2 hours. The absorbance was measured at $450 \mathrm{~nm}$ and all treatments were expressed as the percentage of negative control cells.

\section{T3-L1 cell culture and stimulation}

Murine 3T3-L1 preadipocytes seeded to confluence in a 6 well plate cultured in Dulbecco's Modified Eagle's Medium (DMEM, Gibco, Grand Island, NY, USA) with $10 \%$ Bovine calf serum (BCS, Gibco, USA) and $1 \%$ penicillin/streptomycin (Gibco, USA) incubated at $5 \% \mathrm{CO}_{2}$ at $37^{\circ} \mathrm{C}$ were first administered the heat shock procedure described previously followed by AGN treatment then stimulated for differentiation with DMEM with $10 \%$ fetal bovine serum (FBS, Gibco, USA), $1 \mu \mathrm{m}$ dexamethasone (DEX, Sigma-Aldrich (DEX, Sigma-Aldrich, St. Loius, MO, USA), $0.5 \mathrm{mM}$ isobutylmethylxanthine (IBMX, SigmaAldrich, USA) and $10 \mu \mathrm{g} / \mathrm{mL}$ insulin (INS, Sigma-Aldrich, USA). Then, the media was changed into DMEM supplemented with $10 \%$ FBS and $10 \mu \mathrm{g} / \mathrm{mL}$ insulin every 48 hours until day 8 .

\section{Oil red $O$ staining}

The amount of lipid gained was depicted through Oil red O staining of 3T3-L1 preadipocytes treated with 
different concentrations of AGN. The differentiated 3T3-L1 were fixated in $10 \%$ formaldehyde for one hour then washed with distilled water. Isopropanol was then added in each well prior to staining proper. The cells were stained using $0.5 \%$ Oil Red $\mathrm{O}$ solution diluted $(60: 40, \mathrm{v} / \mathrm{v})$ in isopropanol for 15 minutes at room temperature then washed with triple distilled water to further remove excess stain and dried. Differentiation was examined under microscope. Then, the amount of triglyceride was assessed by isopropanol dissolution and optical density measurement at $490 \mathrm{~nm}$.

\section{RNA extraction and real-time polymerase chain} reaction analysis

Confluent cultures of 3T3-L1 cells (G0) in 6-well plates having undergone heat shock procedure followed by treatment of different concentrations of AGN and induction by different solutions as previously described were the source of RNA. Total RNA was extracted from 3T3-L1 at day 8 using RNAiso Plus (Takara Bio Inc., Kusatsu, Japan) to synthesize cDNA from $1 \mu \mathrm{g}$ of total RNA in a $20 \mu \mathrm{L}$ reaction using Maxime RT PreMix Kit (iNtRON Biotechnology, Seongnam, Korea). Polymerase chain reaction (PCR) reactions were initiated by denaturation cycle at $95^{\circ} \mathrm{C}$ for $5 \mathrm{~min}$, followed by 30 amplification cycles: $40 \mathrm{~s}$ at $95^{\circ} \mathrm{C}$, annealing for $40 \mathrm{~s}$ (temperature ranging from $56^{\circ} \mathrm{C}$ to $62^{\circ} \mathrm{C}$ ) and extension at $72^{\circ} \mathrm{C}$ for 1 $\min$.

Oligonucleotide primers of Heat shock factor 1 ( $H S F 1)$, heat shock protein 90 (HSP90), HSP70, HSP60, and HSP27 for the heat stress related genes and PPAR- $\gamma$, CCAAT/enhancer-binding protein alpha $(C / E B P \alpha)$, sterol regulatory element-binding protein 1c $(S R E B P-1 c)$, fatty acid synthase $(F A S)$ and adipocyte protein $2(a P 2)$ for the adipogenic differentiation genes were used in the real-time
(RT)-PCR as enumerated in Table 1.

All of the primers used in this experiment were optimized experimentally. To ensure that RNA for all samples was equivalent, $\beta$-actin was initially subjected to PCR reaction then compared to all gene expression values.

\section{Western blot analysis}

Upon reaching confluence, cells that were seeded in 6 well plates were induced for adipocyte differentiation after the above heat stress procedure and treatments with different concentrations of AGN extract $(0,50,100,200$ and $400 \mu \mathrm{g} / \mathrm{mL}$ ). At day 8 , protein was extracted by adding protein extraction solution (iNtRON Biotechnology, Korea). The lysates were centrifuged at 15,000 rpm for $15 \mathrm{~min}$ at $4^{\circ} \mathrm{C}$ to determine protein content of the supernatant through a modification of Bradford assay. Diluted $35 \mu \mathrm{g}$ of the protein samples were separated by sodium dodecyl sulfatepolyacrylamide gel electrophoresis prior to nitrocellulose membranes transfer. The membranes were blocked with $5 \%$ skimmed milk and hybridized with the following primary Cell Signaling Technology antibodies rabbit polyclonal anti-HSF1 (4356), rabbit polyclonal anti-HSP90 (4874), rabbit polyclonal anti-HSP70 (4872), rabbit polyclonal antiaP2 (D25B3), abcam rabbit polyclonal anti-HSP60 (ab46798), rabbit polyclonal anti-SREBP-1c (ab138663) and rabbit polyclonal anti-HSP27 (sc-13132), rabbit polyclonal anti-PPAR- $\gamma$ (H-100), rabbit polyclonal anti$\mathrm{C} / \mathrm{EBP} \alpha$ (14AA), rabbit polyclonal anti-FAS (A-20) of Santa Cruz Biotechnology, Inc., Dallas, TX, USA. Target proteins were excluded and identified by incubation of the membranes with secondary antibodies conjugated with horseradish peroxidase. To be able to view the exposed target protein, membranes were treated with enhanced chemiluminescence (AB Frontier, Seoul, Korea) then detected on radiographic film.

Table 1. List of primers used in the RT-PCR analysis

\begin{tabular}{|c|c|c|}
\hline \multirow{2}{*}{ Genes } & \multicolumn{2}{|c|}{ Primers } \\
\hline & Forward sequence & Reverse sequence \\
\hline$\beta$-actin & 5'-CAC CCC AGC CAT GTA CGT -3' & 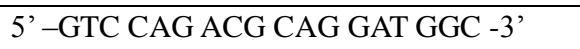 \\
\hline$H S F 1$ & 5’-TGT TTG ACC AGG GCC AGT TT -3’' & 5'- GTT CGA CTG CAC CAG TGA GA -3' \\
\hline HSP90 & 5'- GTG TGC AAC AGC TGA AGG AA -3' & 5'- ACA GCA GCA CTG GTG TCA TC -3' \\
\hline HSP70 & 5'- CGA CCT GAA CAA GAG CAT CA -3' & 5'- ATG ACC TCC TGG CAC TTG TC -3' \\
\hline HSP6O & 5'-CGT TGC CAA TAA CAC AAA CG -3' & 5'- GGC CTC GAA AGT AAC CGG AA -3' \\
\hline HSP27 & 5'- ATC ACT GGC AAG CAC GAA GA -3' & 5'- GGC CTC GAA AGT AAC CGG AA -3' \\
\hline$P P A R-\gamma$ & 5'- GAT GGA AGA CCA CTC GCA TT-3' & 5' - AAC CAT TGG GTC AGC TCT TG -3' \\
\hline$C / E B P \alpha$ & 5'-TGG ACA AGA ACA GCA ACG AG -3' & 5"-TCA CTG GTC AAC TCC AGC AC -3' \\
\hline$S R E B P-1 c$ & 5'-GCT GTT GGC ATC CTG CTA TC -3”' & 5'-TAG CTG GAA GTG ACG GTG GT -3' \\
\hline FAS & 5'-CCC TTG ATG AAG AGG GAT CA -3' & 5'-ACT CCA CAG GTG GGA ACA AG -3' \\
\hline$a P 2$ & 5' - TC AGC GTA AAT GGG GAT TTG G- 3' & 5'-GTC TGC GGT GAT TTC ATC GGA -3' \\
\hline
\end{tabular}

RT-PCR, the real-time polymerase chain reaction; $H S F 1$, heat shock factor 1; HSP, heat shock protein; PPAR- $\gamma$, peroxisome proliferator-activated receptor gamma; $C / E B P \alpha$, CCAAT/enhancer-binding protein alpha; SREBP-1c, sterol regulatory element-binding protein 1c; FAS, fatty acid synthase; $a P 2$, adipocyte protein 2 . 


\section{Statistical analysis}

All experiments were performed three times separately and the results were expressed as means \pm standard deviation. One-way analysis of variance was used to assess the valid differences between means. It was followed by Duncan Multiple Range Test where $\mathrm{p}<0.05$ was considered as statistically significant.

\section{RESULTS}

Angelica gigas Nakai root hot water extract promotes cell proliferation and prevents cytotoxicity due to heat shock in murine 3T3-L1 preadipocytes

Cell viability assay was done to evaluate the effect of AGN concentrations $(0,50,100,200$, and $400 \mu \mathrm{g} / \mathrm{mL})$ on the cell viability of normal and heat shocked murine 3T3L1 preadipocytes. At normal incubation temperature, AGN promotes cell proliferation for both 24 and 48 hours as exhibited by the dose dependent increase in the cell viability percentage presented in Figure 1 and 2. On the other hand, subjecting the cells into heat shock procedure significantly exhibited cytotoxicity as shown by a decrease in cell viability in Figure 1 and 2. Cells without AGN treatment had the lowest cell viability of $61 \%$ and $82 \%$ for both 24 and 28 hours incubation time respectively. However, those groups that received increasing concentrations of AGN (0, 50, 100, 200, and $400 \mu \mathrm{g} / \mathrm{mL})$ were able to compensate for the cytotoxicity brought about by the heat shock procedure based on the dose dependent increase in the cell viability to $82 \%$ and $140 \%$.

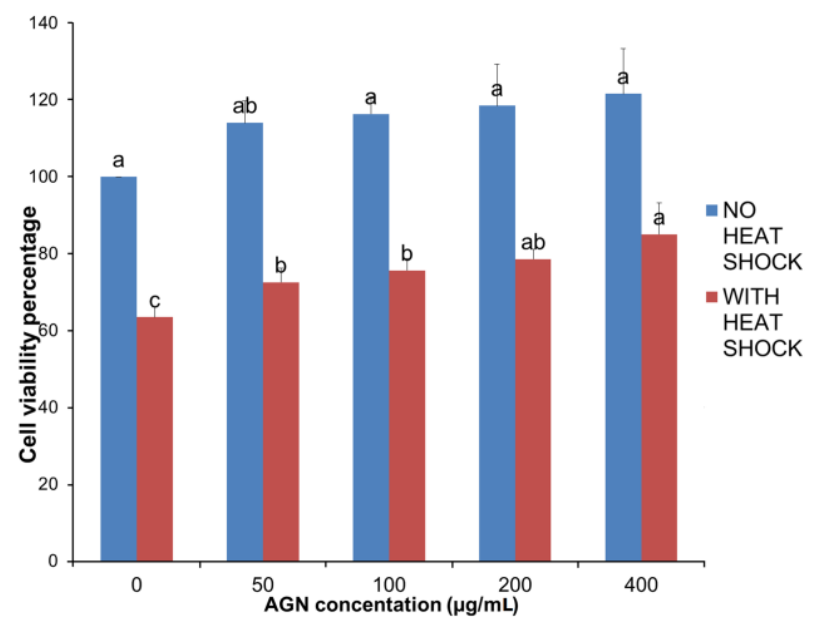

Figure 1. Angelica gigas Nakai root hot water extract promoted cell proliferation on cells subjected to normal incubation temperature $\left(37^{\circ} \mathrm{C}\right)$ and alleviates heat shock by both cytotoxicity prevention and dose dependent cell proliferation among 3T3-L1 cells incubated for 24 hours. The results are expressed as mean \pm standard deviation. Bars with different superscript are significantly different $(\mathrm{p}<0.05)$.

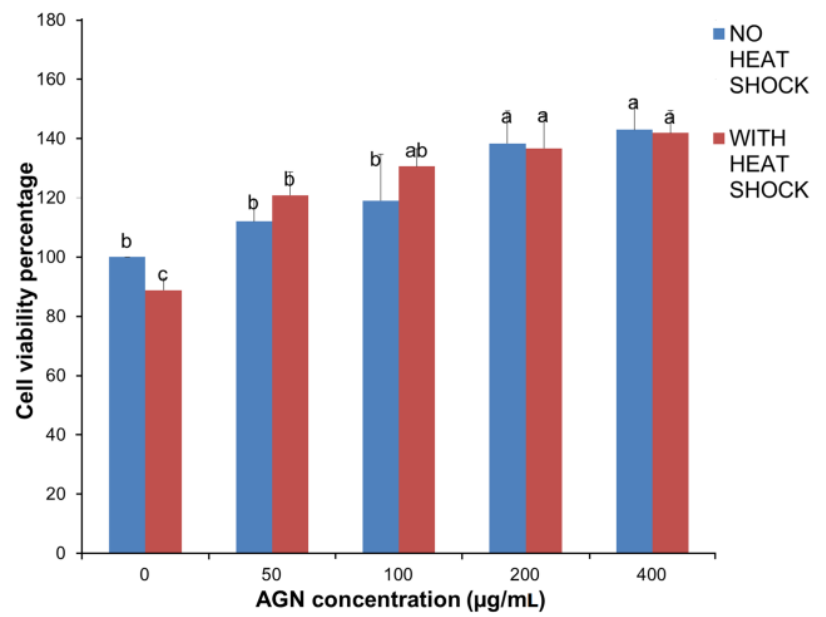

Figure 2. Angelica gigas Nakai root hot water extract promoted cell proliferation on cells subjected to normal incubation temperature $\left(37^{\circ} \mathrm{C}\right)$ and alleviates heat shock by both cytotoxicity prevention and dose dependent cell proliferation among 3T3-L1 cells incubated for 48 hours. The results are expressed as mean \pm standard deviation. Bars with different superscript were significantly different $(\mathrm{p}<0.05)$.

Angelica gigas Nakai root hot water extract increases adipogenic differentiation and intracellular lipid among heat shocked murine 3T3-L1 preadipocytes

Oil red $\mathrm{O}$ staining and triglyceride content measurement was undertaken to observe the effect of AGN root hot water extract in the adipogenic differentiation following heat shock. Oil red $\mathrm{O}$ staining of cells on day 8 showed that increasing concentrations of AGN root hot water extracts enhances adipocyte differentiation (Figure 3). The heat shocked cells without AGN treatment showed reduced differentiation while heat shocked plus $400 \mu \mathrm{g} / \mathrm{mL}$ AGN extract obtained the highest lipid accumulation depicted by the increased number of red stained fat droplets.

To support the subjective micrograph observations in oil red $\mathrm{O}$ staining, elution of oil red $\mathrm{O}$ stain with isopropanol (Figure 3) showed that increasing the concentration of AGN extract in heat shocked cells also increases the triglyceride content of the differentiated adipocytes which may indicate the alleviation of heat stress through AGN root hot water extract treatment.

Angelica gigas Nakai root hot water extract increases heat shock related gene mRNA expression through RTPCR analysis

The oil red $\mathrm{O}$ staining and triglyceride results were further verified and studied in depth by determining the molecular mechanism by which AGN root hot water extract ameliorates heat shock among differentiated murine 3T3-L1. The mRNA expression of several heat shock genes and proteins were analyzed using RT-PCR. Figure 4 shows a dose dependent increase in mRNA expression, supported by the densitometer reading, of both the heat shock gene, 


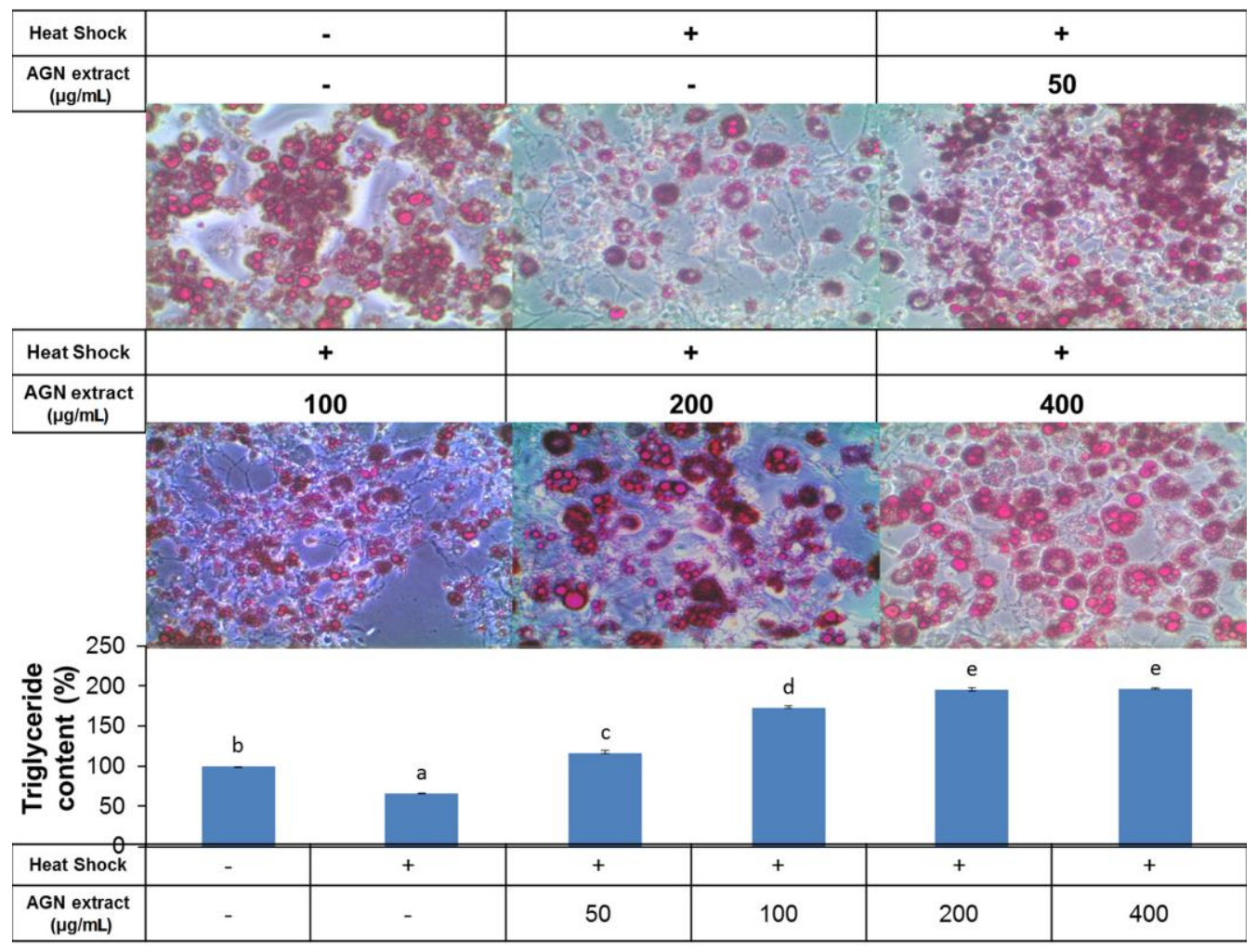

Figure 3. Representative microscopic morphological images of adipocytes stained with oil-red-O after 8 days of differentiation (100x) with its triglyceride measurement at $520 \mathrm{~nm}$. Cytoplasmic lipids are stained red. Values are expressed as means \pm standard deviation of three independent experiments. Means with different superscript were significantly different at $\mathrm{p}<0.05$.

$H S F 1$, which promotes the enhanced expression of several

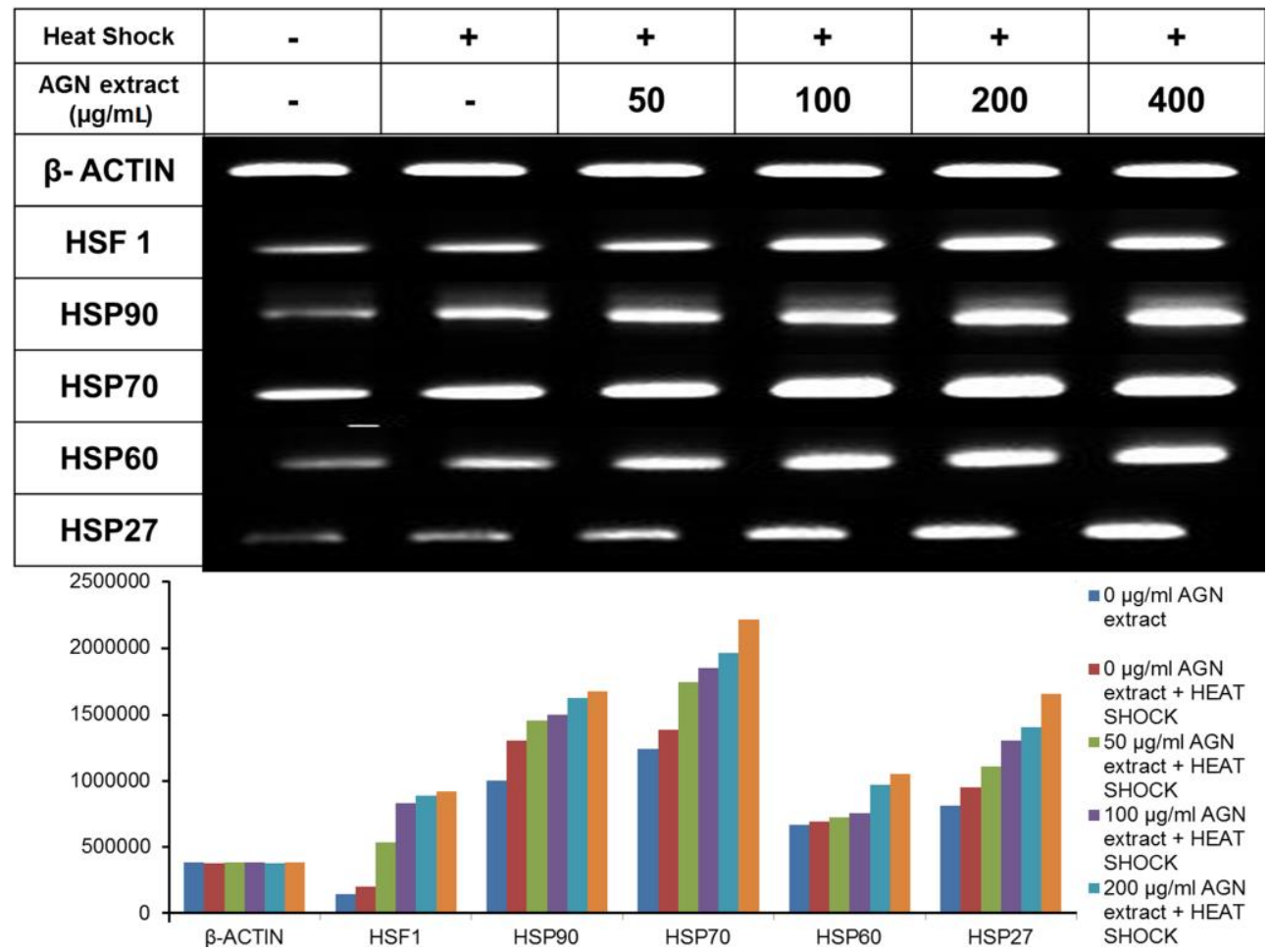

Figure 4. mRNA expressions with densitometry measurements of heat shock related genes in the differentiated murine 3T3-L1 after heat shock procedure at G0 stage, recovery and then treatment with Angelica gigas Nakai root hot water extract (0, 50, 100, 200, and 400 $\mu \mathrm{g} / \mathrm{mL}$ ) prior to differentiation stimulation. 
heat shock proteins and the heat shock related proteins such as HSP90, HSP70, HSP60, and HSP27 thereby protecting the cells on heat stress and prevents apoptosis.

Effect of Angelica gigas Nakai root hot water extract in the expression of genes associated with adipocyte differentiation through RT-PCR analysis

The mRNA expression with densitometry of several transcription factors associated with adipocyte differentiation such as PPAR- $\gamma, \mathrm{C} / \mathrm{EBP} \alpha, \mathrm{SREBP}-1 \mathrm{c}, \mathrm{FAS}$, and $\mathrm{aP} 2$ were analyzed to determine the molecular mechanism governing how increasing concentrations of AGN enhances adipocyte differentiation. Figure 5 shows that there was a significant down regulation of gene expression among those from the positive control which received only heat shock without any AGN extract treatment. Increasing concentrations of AGN extract upregulated genes and proteins associated with adipocyte differentiation even when the cells were subjected to heat shock thereby proving its potential not only to ameliorate heat stress but also helped in controlled lipid metabolism.

Angelica gigas Nakai root hot water extract increases protein expression of heat shock related gene and proteins through Western blot analysis

To further establish the molecular mechanism of AGN extract in protein expression of heat stress amelioration in 3T3-L1 cells, western blot analysis was performed. Figure 6 illustrates the increase in protein expression of the heat stress genes and proteins thus providing a confirmation of the potential of AGN extract in protecting the cell from heat stress.

Effect of Angelica gigas Nakai root hot water extract in the expression of proteins associated with adipocyte differentiation through Western blot analysis

The expression of several proteins associated with adipocyte differentiation such as PPAR- $\gamma, \mathrm{C} / \mathrm{EBP} \alpha$, SREBP1c, FAS, and aP2 were analyzed to determine the molecular mechanism, at the level of protein production, which is the final product of gene expression and process, governing how increasing concentrations of AGN enhances adipocyte differentiation. Figure 7 shows that there is a significant down regulation of protein expression among those cells from the positive control which received only heat shock without any AGN extract treatment. Increasing concentrations of AGN extract upregulated proteins associated with adipocyte differentiation even it is subjected to heat shock thereby proving its potential not only to ameliorate heat stress but also helping in controlling lipid metabolism.

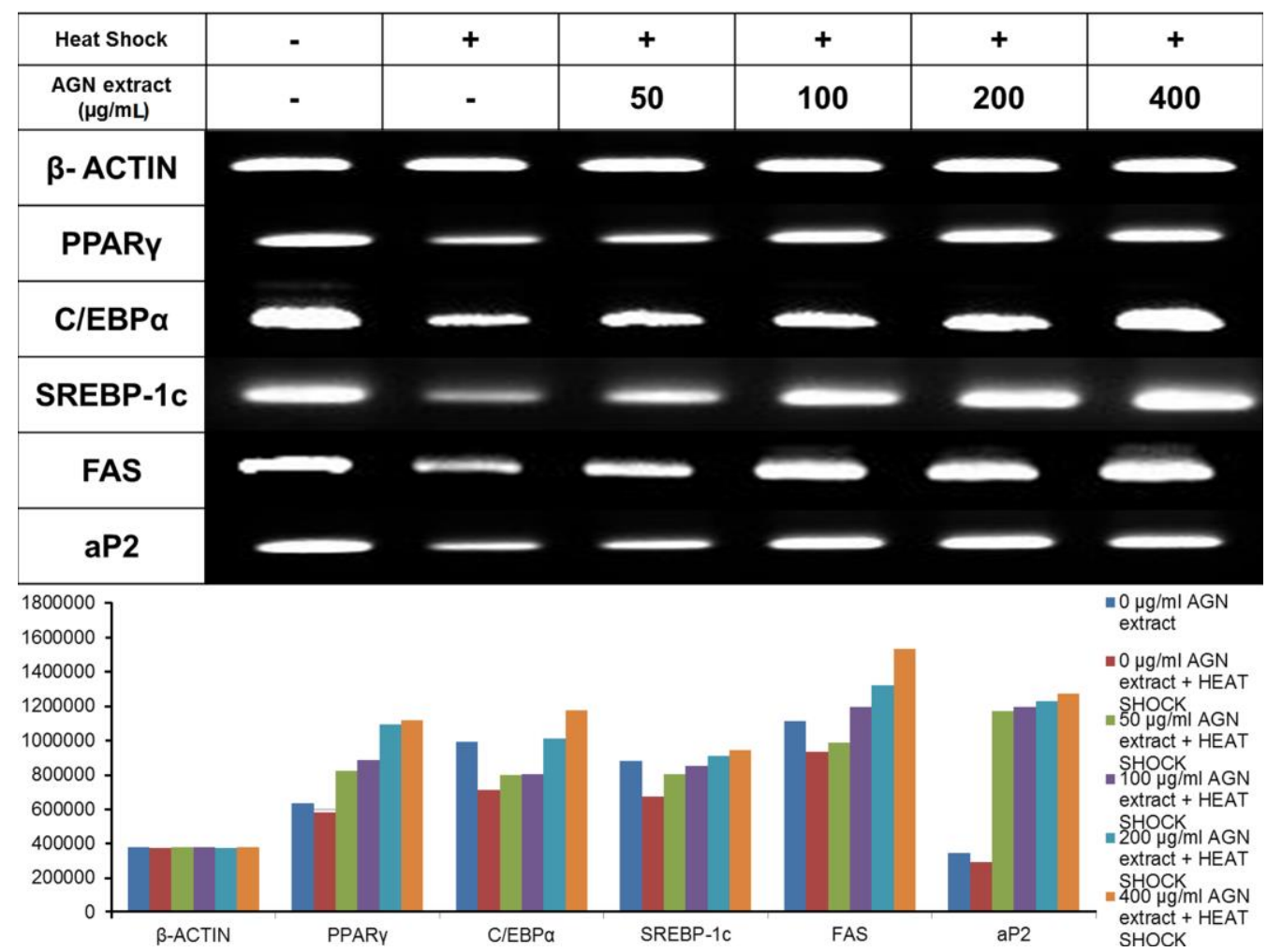

Figure 5. mRNA expressions with densitometry measurements of adipogenic markers in the differentiated murine 3T3-L1 after heat shock procedure at G0 stage, recovery and then treatment with Angelica gigas Nakai root hot water extract (0, 50, 100, 200, and 400 $\mu \mathrm{g} / \mathrm{mL}$ ) prior to differentiation stimulation. 


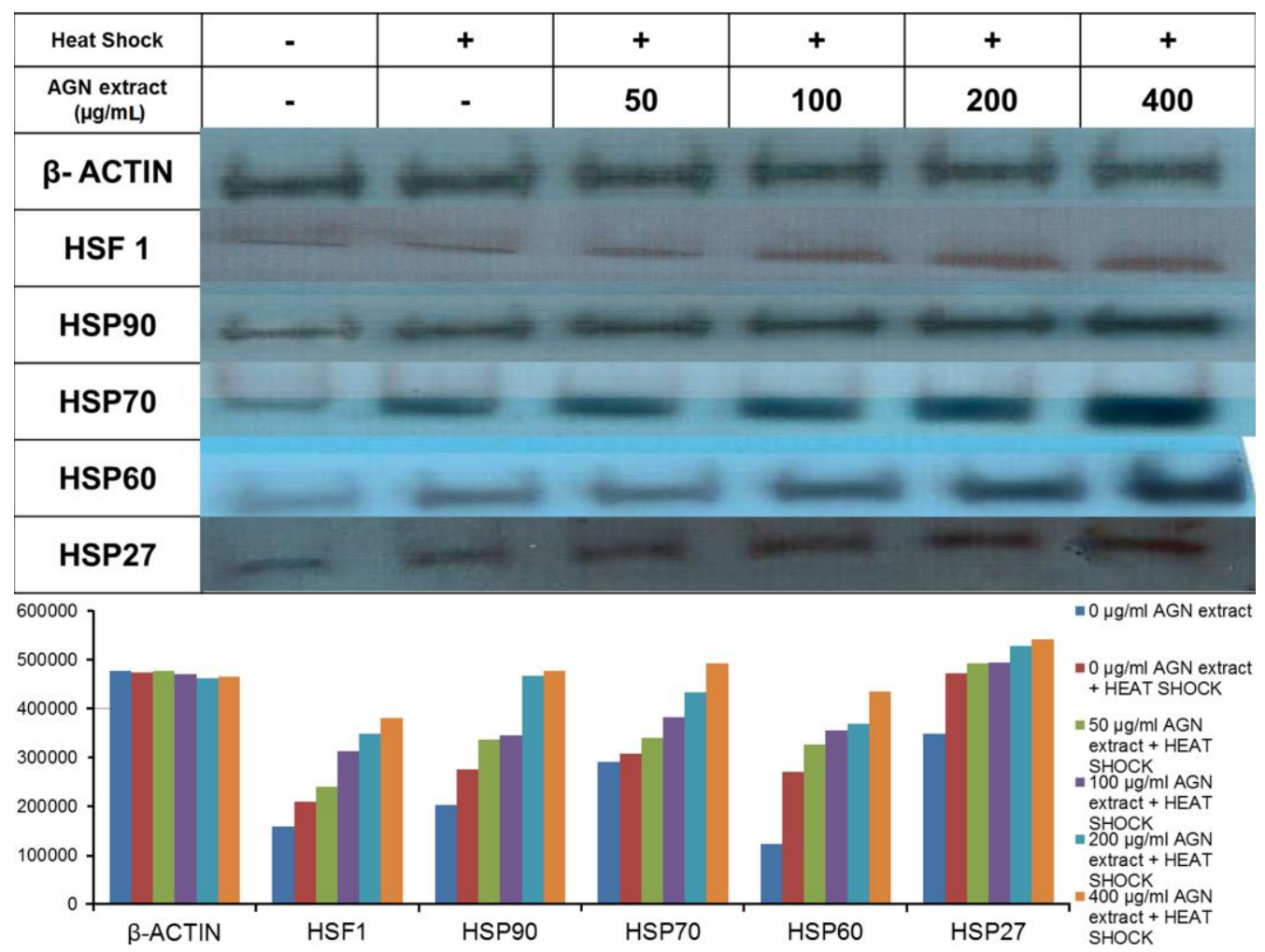

Figure 6. Protein expressions with densitometry measurements of heat shock related genes in the differentiated murine 3T3-L1 after heat shock procedure at G0 stage; recovery and then treatment with Angelica gigas Nakai root hot water extract (0, 50, 100, 200, and 400 $\mu \mathrm{g} / \mathrm{mL}$ ) prior to differentiation stimulation.

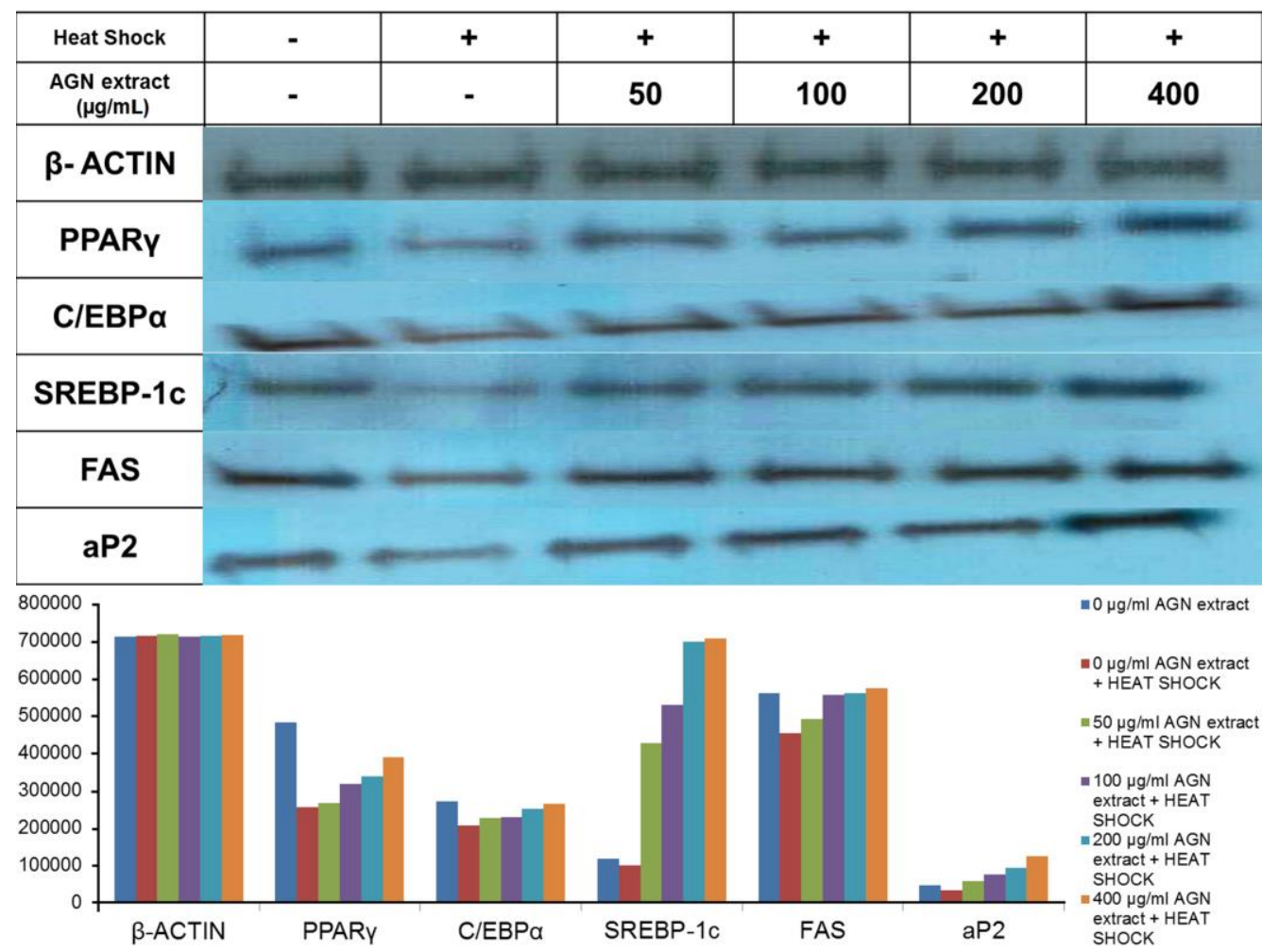

Figure 7. Protein expressions with densitometry measurements of adipogenic markers in the differentiated murine 3T3-L1 after heat shock procedure at G0 stage; recovery and then treatment with Angelica gigas Nakai root hot water extract (0, 50, 100, 200, and 400 $\mu \mathrm{g} / \mathrm{mL}$ ) prior to differentiation stimulation. 


\section{DISCUSSION}

Adipogenesis is a multi-step process involving a cascade of transcription factors and cell cycle proteins regulating gene expression and leading to adipocyte development (Lefterova and Lazar, 2009). Previous study of Dela Cruz et al. (2014) demonstrated the potential of AGN in promoting differentiation of murine 3T3-L1 through the increase in PPAR $\gamma$ and activation of insulin pathway however, its effect on adipogenic differentiation after subjecting the cells into heat shock was still unknown.

Studies have demonstrated that heat shock is associated with alteration in energy metabolism (Bernabucci et al., 2009). Ezure and Amano (2009) specifically investigated the effects of heat stimulation on adipogenesis and found that heat stimulation reduces adipogenesis by decreasing the expression of adipogenesis related transcriptional factors, especially during early adipogenesis.

Generally, cell-based assays are used for screening collections of compounds to determine if the test molecules have effects on cell proliferation or show direct cytotoxic effects that eventually lead to cell death (Riss et al., 2013). The cells incubated at normal temperature and given AGN extract treatment underwent cell proliferation while cells under heat shocked procedure had reduced cell viability measurements that could equate with heat shock being cytotoxic to cells. However, compared to nil treated and heat shocked cells, those that were given AGN showed a dose dependent increase or cell proliferation. Hence, AGN extract promotes cell proliferation under normal incubation temperature and both promotes cell proliferation and prevents cytotoxicity on heat shocked 3T3-L1 preadipocytes.

Confluent 3T3-L1 preadipocytes (G0) were subjected to heat shock procedure same as those in the cell viability assay to attain uniformity during the experiments. Then, the cells can be differentiated synchronously by a defined adipogenic cocktail. Maximal differentiation is achieved upon early hormonal induction for 48 hours with a combination of insulin, glucocorticoids and methylisobutylxanthine, which elevates intracellular cAMP levels in the presence of FBS. Dexamethasone, a synthetis glucocorticoid agonist, is used to stimulate the glucocorticoid receptor (Caprio et al., 2007). Results of the oil red $\mathrm{O}$ staining and intracellular lipid accumulation elusion demonstrated that subjecting 3T3-L1 cells into heat stress prior to the cocktail induction reduces adipocyte differentiation as indicated by a lesser amount of fat formed and a low triglyceride amount but treating the heat stressed cells with different concentrations of AGN showed a greater differentiation and intracellular lipid accumulation. Therefore, AGN root hot water extract has a great potential not just in enhancing adipogenic differentiation as described by dela Cruz et al. (2014) but also has a great potential in ameliorating heat shock by increasing adipogenic differentiation.

The RT-PCR analysis supported the potential of AGN in ameliorating heast shock by increasing adipogenic differentiation through the up regulated expression of several heat shock and adipogenic related transcription genes and proteins such as HSF1, HSP90, HSP70, HSP60, and $H S P 27$ for the former and PPAR $, C / E B P \alpha, S R E B P-1 c$, $F A S$, and $a P 2$ for the latter. The same also has been shown by the Western blot results with an up regulated protein expression of the mentioned heat shock proteins and adipogenic markers.

The resultant increase and accumulation of HSP gives the stressed cell added protection, allowing it to survive. In medicine, evidence is mounting that the ability to survive and adapt to severe systemic physiological stress is critically dependent on the stability of cells to mount an appropriate compensatory stress response (Sonna et al., 2002).

The molecular mechanism by which AGN was able to alleviate heat stress was through enhancing heat shock related genes and proteins which serve as chaperones to the adipogenic genes and proteins. Molecular chaperones are ubiquitous and well conserved proteins which contribute to the essential machinery that binds to other proteins termed clients to support them in the folding process and preserve their conformation (Bukau and Horwich, 1998; Sreedhar et al., 2004). As far as adipocytes are concerned, chaperones have been implicated in the generation of pro-inflammatory mediators in adipocytes (Travers et al., 2012) In line with this, a study of Nguyen et al. (2013) demonstrated that during heat stress, these heat shock proteins were activated and used to protect the cell as chaperones specifically on adipocytes, their main clients would be the proteins responsible for adipogenic differentiation. Stabilizing the heat shock and adipogenic related gene and proteins would result in a continued differentiation process. While on the other hand, insufficiency of those would mean instability for both and differentiation would be halted.

\section{CONCLUSION}

The findings of this study revealed that AGN root hot water extract was able to alleviate heat shock in murine 3T3-L1 adipocytes through heat shock protein augmentation thereby creating a complex with the adipogenic genes and proteins that help protect and enhance the survivability of the cell against death due to heat stress.

\section{CONFLICT OF INTEREST}

We certify that there is no conflict of interest with any financial organization regarding the material discussed in the manuscript. 


\section{ACKNOWLEDGMENTS}

This research work was supported by the National Institute of Animal Science under Rural Development Administration grant (PJ01007603), Jeollabuk-do, Republic of Korea.

\section{REFERENCES}

Bensaude, O., S. Bellier, M. F. Dubois, F. Giannoni, and V. T. Nguyen. 1996. Heat-shock induced protein modifications and modulation of enzyme activities. Stress-Inducible Cellular Responses EXS, 77:199-219.

Bernabucci, U., L. Basiricò, P. Morera, N. Lacetera, B. Ronchi, and A. Nardone. 2009. Heat shock modulates adipokines expression in 3T3-L1 adipocytes. J. Mol. Endocrinol. 42:139147.

Bukau, B. and A. L. Horwich. 1998. The Hsp70 and Hsp60 chaperone machines. Cell 92:351-366.

Caprio, M., B. Fève, A. Claës, S. Viengchareun, M. Lombès, and M. C. Zennaro. 2007. Pivotal role of mineralocorticoid receptor in corticosteroid-induced adipogenesis. FASEB J. 21:2185-2194.

Collier, R. J., L. H. Baumgard, A. L. Lock, and D. E. Bauman 2005. Physiological limitations: nutrient partitioning. Chapter 16. In: Yields of farmed Species: Constraints and Opportunities in the 21st Century. Proceedings: 61st Easter School. Nottingham, England (Eds. J. Wiseman and R. Bradley). Nottingham University Press, Nottingham, UK. 351377.

Collier, R. J. and D. K. Beede. 1985. Thermal stress as a factor associated with nutrient requirements and interrelationships. In: Nutrition of Grazing Ruminants (Ed. L. McDowell). Academic Press, New York, NY, USA. pp. 59-71.

Dela Cruz, J., S. E. Jeong, H. E. Hong, and S. G. Hwang. 2014. The root extract of Angelica gigas Nakai promotes adipogenic differentiation via activation of the insulin signaling pathway in 3T3-L1 cells (854.6). FASEB J. 28:854-856.

Ezure, T. and S. Amano. 2009. Heat stimulation reduces early adipogenesis in 3T3-L1 preadipocytes. Endocrine 35:402-408.

Joo, S. S., D. Park, S. Shin, J. H. Jeon, T. K. Kim, Y. J. Choi, S. H. Lee, J. S. Kim, S. K. Park, B. Y. Hwang, D. I. Lee, and Y. B. Kim. 2010. Anti-allergic effects and mechanisms of action of the ethanolic extract of Angelica gigas in dinitrofluorobenzene-induced inflammation models. Environ. Toxicol. Pharmacol. 30:127-133.
Lacetera, N., U. Bernabucci, L. Basiricò, P. Morera, and A. Nardone. 2009. Heat shock impairs DNA synthesis and downregulates gene expression for leptin and $\mathrm{Ob}-\mathrm{Rb}$ receptor in concanavalin A-stimulated bovine peripheral blood mononuclear cells. Vet. Immunol. Immunopathol. 127:190-194

Lefterova, M. I. and M. A. Lazar. 2009. New developments in adipogenesis. Trends Endocrinol. Metab. 20:107-114.

Li, X., Y. Yang, S. Liu, J. Yang, C. Chen, and Z. Sun. 2014. Grape seed extract supplementation attenuates the heat stress-induced responses of jejunum epithelial cells in Simmental×Qinchuan steers. Br. J. Nutr. 112:347-357.

Lindquist, S. 1986. The heat-shock response. Annu. Rev. Biochem. 55:1151-1191.

Nguyen, M. T., P. Csermely, and C. Sőti. 2013. Hsp90 chaperones PPAR $\gamma$ and regulates differentiation and survival of 3T3-L1 adipocytes. Cell Death Differ. 20:1654-1663.

Park, S. J., J. M. Jung, H. E. Lee, Y. W. Lee, D. H. Kim, J. M. Kim, J. G. Hong, C. H. Lee, I. H. Jung, Y. B. Cho, D. S. Jang, and J. H. Ryu. 2012. The memory ameliorating effects of INM-76, an ethanolic extract of Angelica gigas, against scopolamine- or A $\beta$ (1-42)- induced cognitive dysfunction in mice. J. Ethnopharmacol. 143:611-620.

Riss, T. L., R. A. Moravec, A. L. Niles, H. A. Benink, T. J. Worzella, and L. A. Minor. 2004. Cell Viability Assays. Assay Guidance Manual. Eli Lilly \& Company and the National Center for Advancing Translational Sciences, Bethesda, MD, USA.

Sonna, L. A., J. Fujita, S. L. Gaffin, and C. M. Lilly. 2002. Invited Review: Effects of heat and cold stress on mammalian gene expression. J. Appl. Physiol. 92:1725-1742.

Sreedhar, A. S., C. Soti, and P. Csermely. 2004. Inhibition of Hsp90: A new strategy for inhibiting protein kinases. Biochim. Biophys. Acta. 1697:233-242.

Travers, J., S. Sharp, and P. Workman. 2012. HSP90 inhibition: two-pronged exploitation of cancer dependencies. Drug Discov. Today 17:242-252.

Victoria Sanz Fernandez, M., J. S. Johnson, M. Abuajamieh, S. K. Stoakes, J. T. Seibert, L. Cox, S. Kahl, T. H. Elsasser, J. W. Ross, S. C. Isom, R. P. Rhoads, and L. H. Baumgard. 2015. Effects of heat stress on carbohydrate and lipid metabolism in growing pigs. Physiol. Rep. 3:e12315.

Zhang, J., L. Li, C. Jiang, C. Xing, S. H. Kim, and J. Lü. 2012. Anti-cancer and other bioactivities of Korean Angelica gigas Nakai (AGN) and its major pyranocoumarin compunds. Anticancer Agents Med. Chem. 12:1239-1254. 